\title{
A Spectrum of Ophthalmic Diseases in a Tertiary Care Hospital in Peshawar, KPK; a 10-Year Retrospective Study
}

Muhammad Rafiq Afridi, Khalid Saifullah Baig, Omer Nasim, Salman Khan

Pak J Ophthalmol 2019, Vol. 35, No. 2

See end of article for authors affiliations

Correspondence to:

Omer Nasim

Ophthalmology Unit

Rehman Medical Institute (RMI),

Peshawar

Email:

discover.omer@gmail.com
Purpose: To assess the frequency of different eye morbidities in the patients presenting at a tertiary care Hospital in Peshawar.

Study Design: Cross sectional study.

Place and Duration of Study: Ophthalmology unit of Rehman Medical Institute (RMI), Peshawar from February 2004 to month of March 2014.

Material \& Methods: This research involved accessing the data bank kept by the Hospital. All ocular morbidities seen during the study period was included in the study while those who presented with the diseases of the eye due to some other systemic condition were excluded. Patients were categorized according to their gender and year of admission. The age categories were divided into 5 groups, $0-20,21-40,41-60,61-80,81-100$ years' category. The data collected was analyzed using MS Excel 2013.

Results: A total of 1869 patients were examined out of which $49.92 \%$ were male and $50.07 \%$ were female. The ocular examination revealed that out of the 1869 patients, $57.30 \%$ of the patients suffered from Cataract, $4.86 \%$ patients suffered from Pterygium, $4.76 \%$ suffered from Strabismus, $1.65 \%$ patients suffered from Glaucoma and the remaining $31.43 \%$ suffered from various spectrum of diseases. Female preponderance was more than males in the sense of general morbidity of ocular disorders. 
Conclusion: Cataract was found to be the most common ocular morbidity

found in all age groups.

Keywords: Pterygium, Glaucoma, Cataract, Strabismus.

$\mathrm{T}$ he presentation of eye diseases varies widely all over the globe ${ }^{1,2}$. Specific diseases are common in certain age brackets, races and occupations. ${ }^{2-4}$. Early diagnosis is required in most eye morbidities to prevent loss of sight and to have better prognosis. ${ }^{5}$ Vision is essential for daily activities and any visual impairment is serious and debilitating disability $^{6}$. While some eye morbidities are easily cured and others if not prevented or treated promptly can lead to loss of vision and permanent blindness, therefore it is of paramount importance to find out the trend of eye diseases ${ }^{7}$. Large amount of data is available on anticipation and treatment of the visual deficiency in every single remote district of the World, yet almost no data is accessible on the pervasiveness of visual ailments in Tibetan who live in the remote zones of the Tibetan Plateau ${ }^{8}$.

The prevalence of visual impairment is expected to be higher in the developing countries due to the low level of healthcare services in many of the countries?. Prevalence mapping concerning the weight of a condition (e.g., visual debilitation) at a specific area at a point or period is essential. Accurate prevalence gauges are expected to help in the accessibility of human services, related financial expenses, and personal satisfaction associated with having the condition. Information of such caliber is a basic part in arranging future investigations, having controlled clinical preliminaries in anticipation and appropriate treatment of the morbidity. Currently there is very little data on the prevalence of eye diseases in the north western part of Pakistan The purpose of this research was to discover the pattern of eye ailments in ophthalmology department of Rehman Medical Institute Peshawar.

\section{MATERIAL \& METHODS}

A descriptive retrospective study was done of patients visiting the Ophthalmology unit of Rehman Medical Institute Peshawar from February 2004 to March 2014 by accessing the registers kept by the Hospital. Patients were categorized according to their gender and year of admission. The age categories were divided into 5 groups, 0-20, 21-40, 41-60, 61-80, 81-100 years category. A total number of 1869 patients were found during the ten-year retrospective study.

All patients aged 1-100- years who were admitted in ophthalmology department in RMl Peshawar, having ocular morbidity were included in the study while those presenting with diseases of the eye along with other systemic diseases were excluded.

The Data collected was analyzed using MS Excel 2013. After the collection of data, all the data was entered into MS Excel 2013 and the analyzed results 
are presented as simple frequencies and tables. The data analyzed was based on the number of patients admitted to the Eye unit and the variables under study included major diagnoses i.e. Cataract, Glaucoma, Strabismus and Pterygium.

\section{RESULTS}

The investigation revealed that out of the 1869 patients $49.92 \%$ were male and $50.07 \%$ were female. $57.30 \%$ of the patients suffered from Cataract, $4.86 \%$ patients suffered from Pterygium, $4.76 \%$ suffered from Strabismus, $1.65 \%$ patients suffered from Glaucoma and the remaining $31.43 \%$ suffered from various other diseases (Table 1 and 2).
Table 1: Frequency of Diagnoses

\begin{tabular}{|lcc|}
\hline Diseases & Frequency $\mathbf{( n )}$ & Percent $\mathbf{( \% )}$ \\
\hline Cataract & 1071 & 57.30 \\
Pterygium & 91 & 4.87 \\
Strabismus & 89 & 4.76 \\
Glaucoma & 31 & 1.65 \\
Others & 587 & 31.43 \\
Total & 1869 & 100.0 \\
\hline
\end{tabular}

The third age group i.e. 41 - 60 years presented with the highest proportion of diseases $(38.80 \%)$, while above 81 years group accounted for the least proportion of disease i.e. $1.87 \%$ patients (Table 3). Cataract was the most common disease found in all age groups of patients.

Table 2: Distribution of diseases on the basis of gender.

\begin{tabular}{|lcccccc|}
\hline Gender & Cataract & Pterygium & Strabismus & Glaucoma & Others & Total \\
\hline Male & 515 & 53 & 51 & 19 & 339 & $977(52.27 \%)$ \\
Female & 554 & 38 & 38 & 12 & 245 & $887(47.46 \%)$ \\
Other & 02 & 00 & 00 & 00 & 03 & $05(0.27 \%)$ \\
Total & 1071 & 91 & 89 & 31 & 587 & $1869(100 \%)$ \\
\hline
\end{tabular}

Table 3: Prevalence of diseases on the basis of age of patients.

\begin{tabular}{|c|c|c|c|c|c|c|}
\hline Age (years) & Cataract & Pterygium & Strabismus & Glaucoma & Others & Total \\
\hline $0-20$ & 102 & 6 & 63 & 11 & 239 & $421(22.53 \%)$ \\
\hline $21-40$ & 83 & 46 & 24 & 7 & 101 & $261(13.96 \%)$ \\
\hline $41-60$ & 452 & 36 & 1 & 8 & 145 & $642(34.35 \%)$ \\
\hline $61-80$ & 410 & 3 & 00 & 5 & 96 & $514(27.50 \%)$ \\
\hline 81 and above & 24 & 00 & 00 & 00 & 1 & $25(1.34 \%)$ \\
\hline Nil & 00 & 00 & 01 & 00 & 5 & $6(0.32 \%)$ \\
\hline Total & 1071 & 91 & 89 & 31 & 587 & $1869(100 \%)$ \\
\hline
\end{tabular}

\section{DISCUSSION}

The major ocular morbidity observed in the study was Cataract with 1071 patients i.e. 57.3\%. Females (51.73) were more affected than males (48.08). The age group most affected was 41-60 years with 452 patients $(42.24 \%)$ of all cataract cases. Quite similar results were found in a study conducted by Ahmed et al. at Hayatabad medical complex Peshawar where cataract accounted for $57.5 \%$ patients ${ }^{10}$.

Opacification of the crystalline lens of the eye causes total or partial blindness ${ }^{11}$. Cataract is the leading cause of loss of vision and blindness worldwide and is prevalent in both developed and developing countries. $\backslash^{12}$ Cataract, in fact being highly treatable with minimally invasive surgeries, still accounts for half the world's cases of reversible blindness. In most developing countries, blinding cataract is not only prevalent but is also more severe. And, unfortunately, the curative operative procedures are insufficient ${ }^{13}$.

A Pterygium (from the Greek, pterygos, "little wing") is a wing-shaped, fibrovascular growth that originates from the bulbar conjunctiva and that can chronically spread to the corneal limbus and beyond ${ }^{14,15}$. The total number of cases with pterygium in our study were 91 out of which $58.24 \%$ were males and $41.76 \%$ were females. The age group most affected was $21-40$ years with $50.06 \%$ patients. In another study held in Barbados, the prevalence rate was $11.6 \%{ }^{16}$. Yet 
another study showed a prevalence rate of $10.1 \%$, both of which were quite higher than ours ${ }^{17}$.

The prevalence rate of Squint in our study was $4.76 \%$ with $57.30 \%$ males and $42.70 \%$ females. The age group most commonly affected was 0-20 years with $70.79 \%$ prevalence rate. Strabismus is a problem caused by one or more dysfunctional eye muscles ${ }^{18}$. In a study conducted in Hayatabad medical complex Peshawar, squint was reported in $2.0 \%$ cases which is less than ours ${ }^{10}$. In another study conducted in Riyadh KSA, prevalence of strabismus was also less than that of our study i.e. $1.9 \%$ vs. $4.7 \%^{19}$.

Globally, the second leading cause of blindness is Glaucoma ${ }^{20}$. It is difficult to define glaucoma precisely, partly because the term amalgamates a wide array of diseases. All types of glaucoma have a characteristic optic neuropathy that is associated with visual field loss as harm advances, and in which intraocular pressure is a key factor that can be modified 21,22 . Our study showed the prevalence rate of $1.66 \%$ with $61.29 \%$ males and $38.71 \%$ females. The age group most affected was between 0-20 years.

The ratio of glaucoma in this study was found to be low as compared to another study conducted in Peshawar i.e. $1.66 \%$ as compared to a study conducted in Hayatabad medical complex where the prevalence of Glaucoma was found to be $4.5 \%{ }^{10}$.

Limitations of this study incorporate the study design (retrospective), the site being of a solitary tertiary care hospital and all information was gatered from an inpatient treatment facility. Along these lines, a populace-based study would give more dependable information on Ocular morbidities which would incorporate information from the general outpersistent administrations.

\section{CONCLUSION}

Female preponderance was more than males in the sense of general morbidity of ocular disorders. The most common eye morbidity was found to be; Cataract which does not require any long-term medical treatment. The second most common disease found was Pterygium which was different from most other studies while doing the literature review. Glaucoma was found to be least common eye morbidity in our study.

\author{
Author's Affiliation \\ Muhammad Rafiq Afridi \\ Associate Professor, Consultant Ophthalmologist \\ Rehman Medical Institute (RMI), Peshawar, Pakistan \\ Khalid Saifullah Baig \\ Student, MBBS, Final Year \\ Rehman Medical College, Peshawar, Pakistan \\ Omer Nasim \\ House Officer, Accident \& Emergency (A\&E) \\ Rehman Medical Institute, Peshawar, Pakistan \\ Salman Khan \\ House Officer, General Surgery \\ Rehman Medical Institute, Peshawar, Pakistan
}

\section{Author's Contribution}

Muhammad Rafiq Afridi

Conceived, and designed, did the editing, review \& final approval of the manuscript

Khalid Saifullah Baig

Data collection, statistical analysis \&manuscript writing 


\section{Omer Nasim}

Data collection/correction, manuscript writing \& editing of the manuscript

Salman Khan

Data correction, computer generation of the data bank

\section{REFERENCES}

1. Topalovo AV. Incidence of Eye Diseases in different parts of the World. Ophthalmology, 1984; 6: 374-77.

2. Ajayeoba AI, Scott SCO. Risk factors associated with eye disease in Ibadan, Nigeria. Afr J Biomed Res. 2002; 5: $1-3$.

3. Canavan YM, Oflaherty MJ, Archer DB, Elwood JH. A 10-year survey of eye injuries in Northern Ireland, 196776. British Journal of Ophthalmology, 1980; 64 (8): 61825.

4. Alakija W. Eye morbidity among welders in Benin City, Nigeria. Public Health, 1988 Jul; 102 (4) :381-4.

5. Simon JW, Kaw P. Commonly Missed Diagnoses in the Childhood Eye Examination Albany Medical College, Albany, New York. Am Fam Physician, 2001; 64: 623-29.

6. Pi L-H, Chen L, Liu Q, Ke N, Fang J, Zhang S, et al. Prevalence of Eye Diseases and Causes of Visual Impairment in School-Aged Children in Western China. Journal of Epidemiology, 2012; 22 (1): 37-44.

7. Khatri B, Kashif A. Pattern of Common Eye Diseases in Children in a Tertiary Eye Hospital, Karachi. Pak J Ophthalmol. 2014; 30 (04): 193-98.

8. Pakbin M, Katibeh $\mathbf{M}$, Pakravan $\mathbf{M}$, Yaseri M, Soleimanizad R. Prevalence and causes of visual impairment and blindness in central Iran; The Yazd eye study. Journal of Ophthalmic and Vision Research, 2015; 10 (3): 279.

9. Oduntan, A. Prevalence and causes of low vision and blindness worldwide. African Vision and Eye Health, 2005; 64 (2): 44-57.

10. Ahmad N, Aamir A.H, Hussain I, Ghulam S. Annual prevalence of various diseases in hospitalized patients in a teriary level teaching hospital at Peshawar. Pak J Med Res 2004; 43: 166-71.

11. Jacobs DS. Cataract in adults [Internet]. UpToDate. 2017. Available from:

https://www.uptodate.com/contents/cataract-inadults.

12. Al-Swailmi FK. Global prevalence and causes of visual impairment with special reference to the general population of Saudi Arabia. Pakistan Journal of Medical Sciences, 2018; 34 (3): 751-6.

13. Liu Y-C, Wilkins M, Kim T, Malyugin B, Mehta JS. Cataracts. The Lancet. 2017; 390 (10094): 600-12.

14. Schein OD. The Epidemiology of Eye Disease. New England Journal of Medicine, 1998 Nov; 339 (20): 14823.

15. Hashemi H, Khabazkhoob $\mathbf{M}$, Yekta A, Jafarzadehpour E, Ostadimoghaddam H, Kangari H. The prevalence and determinants of pterygium in rural areas. Journal of Current Ophthalmology, 2017; 29 (3): 194-8.

16. Aminlari A, Singh R, Liang D. Management of Pterygium. Eye Net Mag. 2010; 14 (11): 37-8.

17. Nemesure B, Wu S-Y, Hennis A, Leske MC. Nine-Year Incidence and Risk Factors for Pterygium in the Barbados Eye Studies. Ophthalmology, 2008; 115 (12): 2153-8.

18. Ang M, Li X, Wong W, Zheng Y, Chua D, Rahman A, et al. Prevalence of and Racial Differences in Pterygium. Ophthalmology, 2012; 119 (8): 1509-15.

19. Alsaqr A, Abusharha A, Fagehi R, Almutairi A, Alosaimi S, Almalki A, et al. The visual status of adolescents in Riyadh, Saudi Arabia: a population study. Clinical Ophthalmology, 2018; 12: 965-72.

20. Fan S. Strabismus. xPharm: The Comprehensive Pharmacology Reference, 2009;: 1-3.

21. Glaucoma is second leading cause of blindness globally. Bulletin of the World Health Organization, 2004 Nov; 82 (11): 811-90.

22. Bowling B. Glaucoma. In: Kanski's Clinical Ophthalmology a Systematic Approach, 8th ed. 2016. 